\title{
Letramentos em rede: textos, máquinas, sujeitos e saberes em translação ${ }^{1}$
}

\author{
Networked literacies: texts, machines, \\ subjects and knowledges in translation
}

\author{
Marcelo El Khouri Buzato* \\ Universidade Estadual de Campinas \\ Campinas - São Paulo / Brasil
}

RESUMO: Este trabalho apresenta uma proposta de (re)descrição do fenômeno do(s) (novos) letramento(s) fundamentada teórico-metodologicamente na Teoria Ator-Rede e ilustra o percurso que levou a tal proposta com uma vinheta descritiva de parte dos resultados de um estudo de cunho etnográfico que envolveu dois estudantes universitários do sudeste do Brasil por um período de dois anos. Os dados incluídos no estudo foram gerados por várias estratégias, tais como o monitoramento dos computadores pessoais dos informantes por meio de um software especializado, notas de campo, diários pessoais, observação simples e participante, além de entrevistas semiestruturadas. Objetiva convidar a comunidade de pesquisa em novos letramentos no Brasil a avaliar a utilidade de conceberem-se letramentos e subjetividades como atores-redes, assim como os limites de tal manobra teórico-metodológica. Revisa brevemente estudos sobre (novos) letramento(s) que utilizaram conceitos da Teoria Ator-Rede e conclui que a mesma ainda não foi explorada em todo o seu potencial nesse campo de pesquisa.

PALAVRAS-CHAVE: letramentos, teoria ator-rede, subjetividade, contexto, cultura digital.

ABSTRACT: The study proposes a (re)description of the phenomenon of (new) literacy(ies) on the theoretical-methodological basis of Actor-Network Theory and illustrates the process that led to such a proposal with a descriptive vignette based on some results of a two-year ethnography-oriented study that involved two university students from southeastern Brazil. The data included in the study were generated through various strategies such as monitoring the informants' personal computers, field notes, personal journals, participant and non-participant observation as well as semi-structured interviews. It is intended that the article

\footnotetext{
${ }^{1}$ Trabalho produzido no âmbito do projeto de pesquisa "Letramento, Fronteiras e Cultura Digital”, financiado pela FAPESP sob o número do processo 2009/00671-7.

*mbuzato@iel.unicamp.br
} 
works as an invitation for the literacy research community in Brazil to assess the usefulness of conceiving literacies and subjectivities as actor-networks, as well as the limits of such a theoretical-methodological move. Previous studies on (new) literacy(ies) that used concepts from Actor-Network Theory are reviewed, and it is concluded that the theory has yet to be fully explored in this research field.

KEYWORDS: literacies, actor-network theory, subjectivity, context, digital culture.

\section{Introdução}

Este trabalho pode ser compreendido como uma tentativa, entre outras, de contribuir para a construção de enfoques teóricos alternativos acerca da relação entre práticas e eventos de letramento, e da conexão dessa relação com os processos de subjetivação e construção/produção de conhecimento nas sociedades contemporâneas. Tal enfoque se faz necessário em face das muitas transformaçōes econômicas, técnicas e socioculturais ligadas à disponibilidade das tecnologias da comunicação digital para uma ampla parcela das populaçôes letradas no Ocidente.

Pretende-se, mais objetivamente, oferecer uma (re)descrição do que a literatura vem chamando de novos letramentos, com base em conceitos da Teoria Ator-Rede, e, ao mesmo tempo, apresentar ao leitor um retrospecto do processo que levou à adoção de tal aporte teórico para o projeto de pesquisa aqui focalizado. Tal proposta acarreta, primeiro, a necessidade de apresentaremse ao leitor ainda não familiarizado com a TAR alguns de seus conceitos-chave, e, em segundo lugar, a oportunidade de formular um convite à discussão, nessa comunidade, sobre a utilidade e os limites, para a pesquisa e para o ensino, de conceber-se letramentos e subjetividades como redes heterogêneas.

O trabalho não objetivou mapear biunivocamente cada um dos elementos empíricos invocados em relação a cada um dos conceitos da Teoria Ator-Rede apresentados na seção teórica. Tampouco houve a pretensão de "demonstrar" a teoria exaustivamente, até porque isso seria impossível no espaço aqui disponível. Parte-se, assim, de uma vinheta que resume um dos estudos de caso produzido ao longo do projeto de pesquisa a que o texto está vinculado, e, em seguida, apresenta-se um conjunto de conceitos da TAR que parecem esclarecer, e aprofundar, alguns dos pontos reunidos no caso em foco. Conclui-se com algumas afirmações genéricas sobre letramento, a partir da ótica proposta, as quais possivelmente darão margem a discussões futuras sobre sua viabilidade e utilidade. 


\section{Letramentos e sujeitos como redes heterogêneas}

Já há algum tempo, alguns autores preocupados com os efeitos do que poderíamos chamar de "digitalização da cultura" vêm tentando (re)descrever $\mathrm{o}(\mathrm{s})$ (novos) letramento(s) a partir de conceitos operativos ${ }^{2}$ que propiciem uma aproximação entre o que se está observando empiricamente no quotidiano dos letrados "conectados" e os saberes "sedimentados" no campo dos estudos sobre o letramento. Entre esses conceitos operativos estão o de dêixis (COIRO et al., 2008), fronteira (BUZATO, 2008, 2009a) e rede (BUZATO, 2009b e LEANDER; LOVVORN, 2006, entre outros).

Dizer que letramento "tornou-se um dêitico" é apenas reafirmar, em face de evidências indisputáveis, o que, por outras operações conceituais, já está pressuposto quando falamos em letramentos no plural, concebendo-os como práticas sociais situadas: os valores do letramento só podem ser "atualizados" em contextos. Contextos, por sua vez, são sempre caracterizados por uma relação dinâmica entre modelos culturais abstratos (chamados de práticas de letramento nessa tradiçāo) e artefatos tecnológicos, sistemas de representação e relaçôes sociais postos em açãa, em determinados tempos e espaços, por meio do que chamamos de eventos de letramento.

Tratar de letramentos passando pelo conceito de fronteira é, por sua vez, reconhecer que os contextos de que falam as teorias do letramento no plural são sempre heterogêneos e, portanto, loci do conflito, da contaminação e da demarcação de limites entre culturas, tecnologias, semioses e discursos. Para ilustrar com um exemplo (hipotético) do quotidiano escolar, imagine-se que um aluno, a quem o professor encomendou uma pesquisa escolar, decida tomar palavras alheias, achadas num blog ou mandadas por amigos a quem pediu socorro em um serviço de rede social online, para produzir o que se poderia chamar de um simples remix, em lugar de retextualizar o que encontrou online, produzindo um texto escolar com "suas próprias palavras". Não é difícil prever que, habituada a identificar falhas de coesão ou incoerências em textos escolares

\footnotetext{
${ }^{2}$ Entendo por "conceito operativo" todo aquele conceito que se caracteriza não por sua definição temática ou objetiva, mas pelo tipo de operação intelectual (heurística) que ele permite realizar independentemente do tema ou objeto da reflexão a que é aplicado.
} 
tradicionais, a professora localizasse o que, do lado da fronteira onde está o aluno, teriam sido "vacilos" de montagem. ${ }^{3}$

Digamos ainda que, sentindo-se traída e desrespeitada, a professora punisse o aluno por plágio, baseada em um significado dado à autoria individual de um texto que não vigora, necessariamente, nos contextos de produção textual de que vieram os elementos de seu remix.

A ideia de fronteira, nesse caso, ajuda a revelar o lugar de um encontro violento entre duas culturas letradas, mas também a possibilidade de reabertura dos sentidos de texto, autoria e trabalho (intelectual) em cada um dos lados envolvidos. O mais engraçado (ou triste?) nisso, como o é em todo conflito intercultural, é que ambos os personagens do exemplo teriam feito o que, para si, seria o mais coerente. Ao solicitar o resultado da pesquisa "redigido com as próprias palavras", a professora teria pretendido, talvez, promover a integração de conteúdos "novos" a outros já estocados no cérebro do aluno, e mantê-los lá, disponíveis, em caso de necessidade futura (just in case). Já o jovem, ao remixar o que outros já haviam dito em outros lugares, de alguma forma teria recontextualizado aquele conhecimento, como queria a professora, mas sem a preocupação de guardá-lo na memória. Mas o teria feito baseado na certeza de que tal conteúdo poderia sempre ser obtido, e novamente remixado, se e quando necessário (just in time), com um par de cliques. Queria a professora, talvez, que o aluno pudesse guardar o conhecimento em seu corpo, para levá-lo a outros lugares, onde fosse necessário lidar com pessoas e máquinas. Isso seria, contudo, desnecessário para quem, como o aluno, experimenta a memória como uma coisa coletiva e distribuída, estocada para muito além do corpo, numa rede de pessoas e máquinas que podem vir até ele imediatamente, quando necessário.

Isso nos reconduz ao conceito de rede; mais especificamente, à percepção de que letramentos são, e sempre foram, redes de competências, habilidades, textos, propósitos, regras e tecnologias distribuídos por diferentes materiais, lugares físicos e regimes institucionais. Contudo, afirmar que letramentos são redes seria simplesmente ampliar o rol das metáforas já mencionadas, a menos que se explique o significado teórico-metodológico da afirmação e, juntamente

\footnotetext{
${ }^{3}$ Em verdade, a falta de elementos marcadores de coesão específicos e explícitos é justamente uma das características centrais do remix, cuja "textualidade" é produzida por meio de técnicas de montagem cinematográfica ou bricolagem em sentido mais amplo. O "vacilo", nesse caso, teria consistido na não inserção de um ou mais desses elementos coesivos reconhecidos pela professora para que o remix "passasse como" texto escolar.
} 
com isso, o tipo de rede de que se está falando, já que cada tipo traz consigo pressupostos e consequências conceituais.

$\mathrm{Na}$ maioria das vezes em que falamos em redes, temos em mente redes homogêneas (LATOUR, 1996), isto é, um conjunto de entidades, consideradas como sendo da mesma natureza, ligadas entre si por meio de fluxos materiais ou simbólicos. Nesse caso, falamos em países que trocam pessoas ou mercadorias com outros países; empresas que trocam produtos ou dinheiro com outras empresas; pessoas que trocam mensagens ou vírus com outras pessoas; máquinas que trocam impulsos elétricos ou dados numéricos com outras máquinas, e assim por diante.

Mas se tomarmos letramentos como práticas sociais situadas, e não como entidades fixas, redes homogêneas não nos servem. Será necessário pensar em redes do tipo heterogêneo (LATOUR, 1996). Uma rede heterogênea representa uma prática social no sentido de que congrega entidades de tipos distintos (humanas e não humanas, concretas e abstratas, materiais e imateriais) cujo trabalho é compartilhado, e cujas identidades são definidas por uma dinâmica relacional. O que conecta as entidades de uma rede heterogênea são ações, continuamente deslocadas e traduzidas na linguagem de cada uma das entidades relacionadas. As entidades, ou atores, dessa rede, por sua vez, não são tidas como discretas e autocontidas, mas como redes em si mesmas, ou atores-redes.

\section{Tipos de redes}

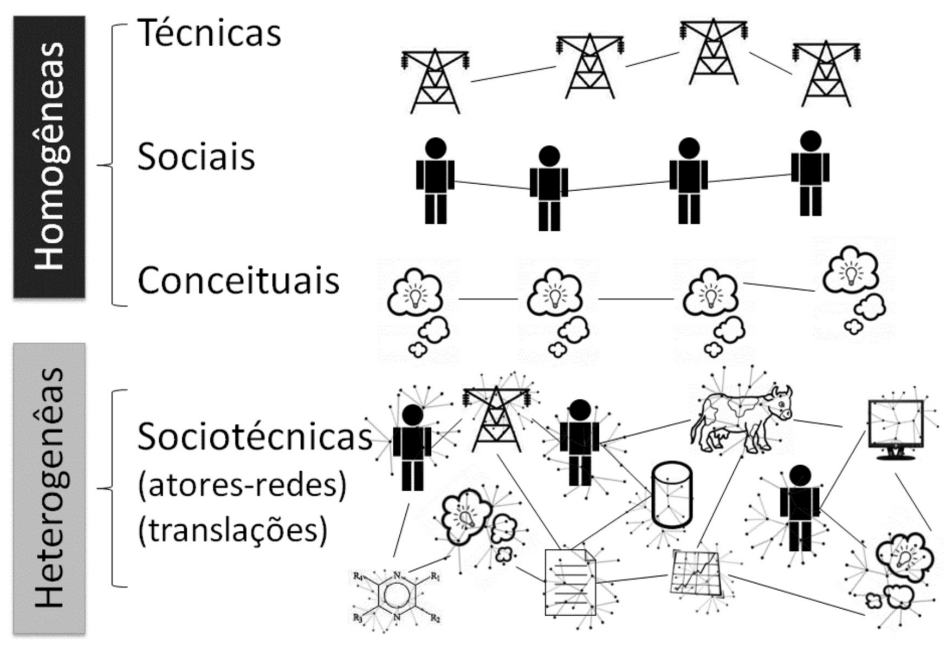

FIGURA 1 - Tipos de redes segundo Latour (1996) 
Já deve estar claro para o leitor que o conceito de rede heterogênea utilizado neste trabalho vem atrelado ao aporte teórico-metodológico específico da Teoria Ator-Rede (doravante TAR), um conjunto não unificado de métodos e princípios metateóricos oriundo do campo dos Estudos Sociais da Ciência e Tecnologia há aproximadamente vinte e cinco anos, que atualmente é utilizado em diversos campos de pesquisa, inclusive no dos estudos do letramento (BRANDT; CLINTON, 2002; HAMILTON, 2001; CLARKE, 2001 e 2002, BARTON; HAMILTON, 2005, LEANDER; LOVVORN, 2006, entre outros).

Fundamentada, em parte, na semiótica da Escola de Paris, a TAR propunha-se, inicialmente, a descrever os processos pelos quais fatos científicos e inovações tecnológicas são construídos e, eventualmente, estabilizados, tornando-se "caixas pretas", ou então desintegrados, antes mesmo de chegarem a existir concretamente. De sua origem até o presente, a TAR foi sendo aplicada em diversos campos de estudo até se tornar suficientemente abrangente para abarcar qualquer tipo de fenômeno associativo que reúna entidades humanas e não humanas em cadeias de tradução e deslocamento de forças e significados. ${ }^{4}$

A estratégia metodológica básica da pesquisa a que este trabalho está vinculado consistiu em se tomarem tanto os sujeitos letrados quanto os letramentos aí focalizados como redes heterogêneas, ou atores-redes, para, em seguida, utilizarem-se conceitos da referida teoria de modo a (re)descrever o que temos chamado de novos letramentos, buscando conhecer as vantagens e limites de tal estratégia. Julga-se, no entanto, que o leitor terá melhores condições de avaliar a plausibilidade dessa proposta conhecendo alguns elementos concretos envolvidos no percurso de sua elaboração, razão pela qual foi montada a vinheta apresentada na seção seguinte.

\section{Caso T., uma vinheta}

T. era um jovem de vinte anos, estudante do curso de Letras em uma universidade pública paulista, que prestara, antes, vestibular para Direito, não por vocação, segundo declarou em entrevista, mas porque isso lhe daria a oportunidade de frequentar um espaço arquitetônico pelo qual tinha grande fascínio: o prédio da Faculdade de Direito do Largo de São Francisco, em São Paulo. Para quem não o conheceu pessoalmente, esse pode parecer um motivo

\footnotetext{
${ }^{4}$ Para uma introdução aprofundada à teoria, ver Latour (2005).
} 
absurdo; contudo, para quem o seguiu por algum tempo, observando e participando de seus letramentos, é possível perceber a coerência do critério, assim como a fonte do fascínio.

Filho de um pequeno empreiteiro e de uma funcionária administrativa formados no ensino superior, $T$. foi criado em uma cidade de aproximadamente cinco mil habitantes, a aproximadamente $160 \mathrm{~km}$ da capital do estado. A cidade cresceu ao redor de uma parada de trem, já desativada, e vive basicamente de agroindústrias que atraem, todos os anos, um grande contingente de trabalhadores rurais vindos de outras partes do Brasil. Essa população temporária habita um lado da cidade oposto ao da família de T., um local considerado "território proibido" por seus pais, já que, em torno das muitas pensōes em que se hospedam os trabalhadores rurais, há bares e prostíbulos que dão contexto à maior parte dos "casos de polícia" da cidade.

Do lado de cá da ponte, dois espaços físicos foram muito importantes na vida de T.: uma lanhouse, na qual se encontrava com amigos desde a infância, e uma praça, onde esse mesmo grupo se reunia, antes da existência da lanhouse, para trocar CDs, revistas, livros e narrativas sobre heavy metal. Um terceiro espaço importante para ele, já à época da pesquisa, era uma igreja evangélica, cujos cultos, animados por música gospel, ele acompanhava, em suas palavras, "da porta pra fora".

Segui T. por esses e outros lugares (físicos e virtuais), fazendo observações ou por meio de dados gerados por um software de monitoramento ${ }^{5}$ instalado em seu computador pessoal, com seu consentimento livre e esclarecido. Ele mesmo recolhia os registros do programa a cada duas ou três semanas e os enviava a mim, para serem organizados e pré-analisados antes das entrevistas periódicas nas quais minhas hipóteses sobre eles eram esclarecidas. ${ }^{6}$

\footnotetext{
${ }^{5}$ Spector Pro - 2009, Spector Soft: Vero Beach, EUA.

${ }^{6} \mathrm{O}$ informante tinha a oportunidade, consentida pelo pesquisador, de remover registros considerados excessivamente privados para serem compartilhados. Pediuse ao informante apenas que alertasse o pesquisador sobre a exclusão/omissão de registros, informando sua localização na sequência dos dados e oferecendo, se possível, uma justificativa. Foram excluídas, de acordo com T., umas poucas conversas com a namorada, e-mails com assuntos de família, e páginas de serviços bancários ou outras quaisquer que contivessem senhas. É possível supor, ainda, que T. tenha removido, sem alertar o pesquisador, itens relacionados à pornografia e/ou sexo virtual, uma vez que afirmou utilizar o computador ocasionalmente para tal finalidade em uma das entrevistas.
} 
No início do trabalho, fiquei sabendo que T. gostava de literatura romântica e de ler e escrever um certo tipo de poesia que, a princípio, eu jamais poderia conciliar com heavy metal ou videogames. No excerto 1, destaco uma estrofe de um dos poemas que ele havia publicado em um fórum de discussão hospedado por um site especializado em jogos de RPG (Role-playing games).

Excerto 1

Parte de um poema de T. (com ênfase adicionada)

No vale sinistro, ouço tantálico cantar

Serafim, trombetas e odes ao divinal

Que divino é este? Oh, maldito sonhar!

E dos abismos profundos, sobe vorpal

Ecos d'uma lamuria que fazem anjos chorar

Oh! Ventos uivantes, estes clamam o mal!

Oh! Maldito demônio sombrio, alva estrela!

Será que a paz um dia eu poderei tê-la?

Embora alguns dos poemas de T. fossem heterométricos, suas composiçôes eram, em geral, baseadas em formas clássicas e rígidas tais como sonetos alexandrinos. Juntamente com esse investimento na precisão formal, chamaram-me a atenção nesses poemas algumas escolhas linguísticas que eu qualificaria como incomuns para um jovem universitário brasileiro contemporâneo.

T. utilizava, por exemplo, os pronomes "tu" " "vós" para a segunda pessoa, flexionando os verbos em seus predicados conforme a norma padrão, algo que não se repetia em nenhum dos outros gêneros que compunham o corpus, nem tampouco na variedade do português falada na região de onde ele vinha. Também chamavam a atenção certas palavras cujo significado, confesso, tive que consultar no dicionário, e que me soavam sensivelmente extemporâneas e/ou exotópicas.

Produzi uma lista de todos os substantivos utilizados por T. nesses aproximadamente setenta poemas e a submeti a um software de análise semântica, ${ }^{7}$ o qual me devolveu como resultado uma relação dos campos lexicais ativados. O que pretendia com isso era simplesmente ter uma ideia, mesmo que vaga, do universo temático desse conjunto de poemas, já que substantivos desempenham, essencialmente, a função de representar a experiência do falante no mundo. Como esperado, em se tratando de textos subjetivos, em que T. fala

7 Tropes, Cyberlex: Lisboa. 
de suas angústias, desejos, frustrações e experiências, os itens mais frequentes remetiam aos campos "vida humana", "vida em sociedade" e "indivíduo". Mas, surpreendentemente, "magia e ocultismo" e "religião e mitologia" apareciam misturados com "transportes" e "comunicação e mídias", dentro de uma mesma faixa quantitativa, como demonstra a Figura 1.

É óbvio que, se realizássemos o mesmo levantamento nos textos produzidos por qualquer pessoa letrada, encontraríamos conexões surpreendentes entre universos temáticos; também é certo que, em se tratando de poesia, a escolha dos substantivos neste caso reflete, mais do que em outros, funções de linguagem outras (poética, metalinguística, emotiva etc.) que não necessariamente a referencial. Ocorre que, à luz dos registros colhidos pelo software de monitoramento, essas conexōes semânticas ganharam um significado metodológico importante: a trama entre campos semânticos urdida nos poemas era uma outra face das trajetórias entre textos e letramentos registradas no software. Dito de outra forma, ao mesmo tempo em que a trama o constituía como poeta, a trajetória permitia a $\mathrm{T}$. descontextualizar-se e recontextualizar-se enquanto sujeito letrado.

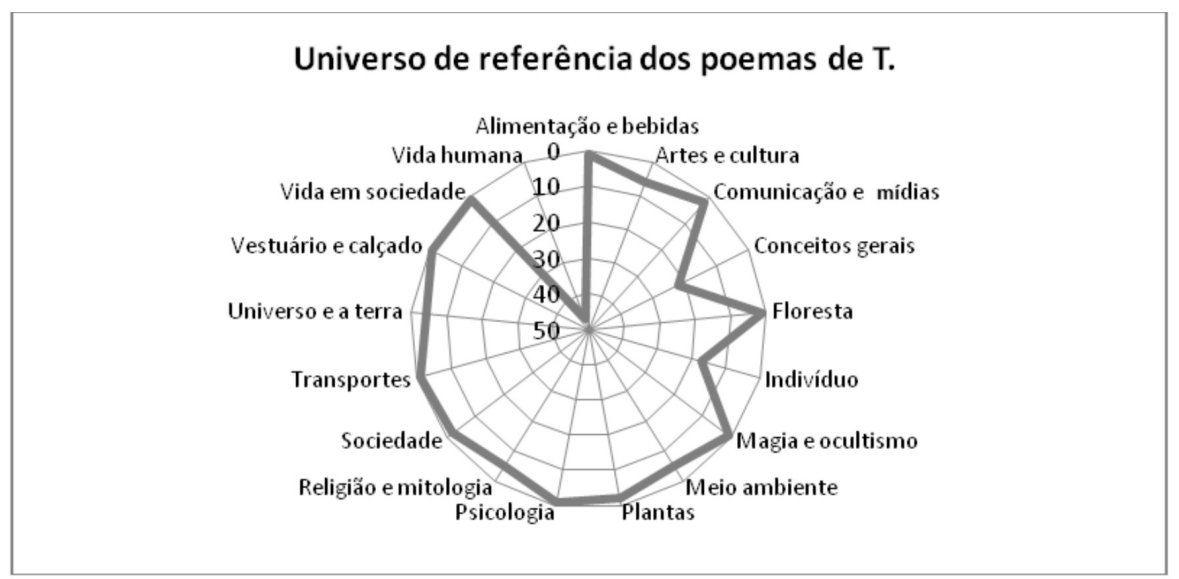

FIGURA 2 - Campos semânticos a que remetem os substantivos nos poemas de T.

${ }^{8}$ É óbvio que esses resultados quantitativos teriam que ser olhados com muito cuidado. Por exemplo, o fato das ocorrências no campo "vida humana" serem muito frequentes pode ser explicado pela pertinência a esse campo de substantivos igualmente representados em campos como "arte e cultura" e "alimentação e bebidas". Importa, entretanto, mostrar que campos mais especializados tais como "ocultismo" e "mitologia" são acionados pelo menos com a mesma frequência que campos afetos à vida quotidiana, tais como "transportes" ou "vestuário", o que revela algum tipo de singularidade. 
Uma das estratégias que adotei para tentar entender essa relação entre intertextualização e recontextualização foi justamente rastrear os vínculos perceptíveis entre certas escolhas linguísticas e procedurais de T.. Por vezes, seguia as palavras, imagens ou modos de agir que me pareceriam "estranhos". Outras vezes, seguia o próprio T. por lugares online e offline que me eram estranhos: lanhouses, universos de RPG online multiusuário (MMORPG), redes sociais mantidas via Orkut e MSN, etc.

Ao fazê-lo, seguia, também, cadeias de ressemiotização (IEDEMA, 2003) de representaçóes de si e do mundo produzidas por T.: pessoas da faculdade e da cidade natal de T., por exemplo, viravam personagens mitológicos em seus poemas ou avatares de um MMORPG; igrejas do Brasil colônia, cujas fotos encontrei em seu computador, apareciam também em suas narrativas entusiasmadas sobre poetas ultrarromânticos que apreciava e buscava imitar; figuras e actantes de contos e romances de fantasia lidos por $T$. na adolescência reapareciam em sistemas de RPG que encontrei entre seus livros, e depois na forma de cosplayers que frequentavam os mesmos encontros de fãs a que $\mathrm{T}$. comparecia eventualmente, para, finalmente, ressurgirem como objetos de pesquisa de um projeto de iniciação científica que $T$. tentava elaborar à época.

Tal estratégia não forneceu qualquer insight novo porque minha visão sobre esses dados continuava vinculada à ideia de uma rede homogênea ligando texto a texto, pessoa a pessoa e contexto a contexto. Passou a fazer sentido apenas quando T. e seus letramentos foram tomados como redes heterogêneas. Dito de outra forma, T. não apenas promovia a circulação desses temas, personagens, palavras e narrativas por diferentes mídias, semioses e contextos espaciotemporais: ele se constituía como T., sujeito letrado, ao deixá-las circularem por ele, como sugere o Excerto 2, produzido no âmbito de um letramento escolar:

\section{Excerto 2}

Trecho de trabalho escolar produzido por $\mathrm{T}$.

Com os grupos montados e os jogadores definidos, fica a cargo do "mestre" de cada grupo escrever a pré-aventura e iniciar o jogo. A função do professor aí passa a ser de ajudar nas construções das aventuras e nos sistemas de regras, o professor também pode fazer com que os "mestres" façam inserçôes de elementos da literatura portuguesa e brasileira nas aventuras. Outro fator de destaque é que o professor pode e deve assumir papel de personagem NPC (Non-player Character) nas aventuras de todos os grupos da sala, podendo assim desenvolver desafios e instigar o processo lógico dos alunos. 
Assim como incorporava temas, palavras e até mesmo posicionamentos perante fatos do quotidiano vindos da literatura de fantasia e dos RPGs em seus textos, T. utilizava subjetificadores (usernames, neste caso) que recolocavam tais elementos em circulação, mas agora inscritos e uma outra materialidade. No Quadro 1, reúno alguns dos usernames utilizados por ele em diferentes momentos, perante diferentes interlocutores, ou em diferentes canais de comunicação mediada por computador. Não vou citar por completo os nomes porque isso possivelmente comprometeria a privacidade $\mathrm{da}$ identidade civil de T., mas ofereço ao leitor descriçóes de seu significado e de seu contexto de uso.

\section{QUADRO 1}

Nomes de usuário de T. em diferentes situações de uso de CMC e suas origens

\begin{tabular}{|l|l|}
\hline $\begin{array}{l}\text { Nomes de usuário } \\
\text { utilizados por T. }\end{array}$ & $\begin{array}{l}\text { "(é o meu) Apelido em <cidade de origem de T.>. Trata-se de uma } \\
\text { palavra em italiano e também é o nome de uma banda de heavy metal } \\
\text { (...), ganhei esse apelido por conta de gostar do som dessa banda". }\end{array}$ \\
\hline $\mathrm{R}^{* * * * *}$ & $\begin{array}{l}\text { "Veio das partidas de RPG. (...) é o nome de um personagem de um } \\
\text { dos romances de Dungeons \& Dragons. (...) o curioso é que existem } \\
\text { pessoas com esse nome de verdade, se procurar no Google vai encontrar, } \\
\text { mas eu utilizo esse pseudonimo apenas no endereço de e-mail." }\end{array}$ \\
\hline $\mathrm{L}^{* * * * *}$ & $\begin{array}{l}\text { "Bom, essa é uma palavra em inglês que significa bruxo. Eu utilizo no } \\
\text { e-mail e utilizava como nick nos fóruns que eu frequentava qdo } \\
\text { comecei a utilizar a internet." }\end{array}$ \\
\hline $\mathrm{W}^{* * * *}$ & $\begin{array}{l}\text { "Esse é o nick de um antigo character do World of Warcraft, esse nome } \\
\text { veio de um romance escrito por Neil Gaiman? que se chama Belas } \\
\text { Maldiçöes (...)." }\end{array}$ \\
\hline $\mathrm{A}^{* * * * *}$ & $\begin{array}{l}\text { "É o nome do meu atual character do universo de RPG multiusuário } \\
\text { online>. Esse nome veio do livro (...) de JRR Tolkien. É o nome de um } \\
\text { local onde (...)." }\end{array}$ \\
\hline $\mathrm{N}^{* * * * *}$
\end{tabular}

${ }^{9}$ Neil Gaiman é um romancista, roteirista de cinema e autor de histórias em quadrinhos. Suas narrativas se aproximam dos poemas de T. no sentido de que também misturam personagens e formatos "clássicos" com temas da mitologia e ocultismo para criar um universo "fantástico" no qual os eventos do quotidiano são permeados pelo sobrenatural. 
Os diferentes usernames de T., concluí, marcavam diferentes etapas de sua vida, além de registrar afinidades (literárias, musicais e de RPG) que o definiam perante os grupos de que participava. Por outro lado, cada nome marcava, também, um tipo de contextualização de si que organizava práticas que atravessavam contextos, interlocutores e lugares geográficos e/ou institucionais. Noto que o segundo desses nomes era o mesmo que T. utilizava no endereço de e-mail por meio do qual se correspondia comigo. Penso que isso apontava para um espaço interacional fronteiriço que vinha sendo alargado entre nós, ou seja, uma prática fronteiriça (a própria pesquisa que realizamos colaborativamente) em que as delimitações entre institucional/público, pessoal/privado, professor (quem ensina)/aluno (quem aprende) estavam temporariamente suspensas. É isso que estaria em foco no comentário no qual ele me avisava que $\mathrm{L}^{* * * * *}$ habitava dois mundos, como nome civil e como nome de personagem ou jogador em RPG. Aqui novamente, como nos poemas e no trabalho escolar do Excerto 2, T. utilizava o que se pode chamar de objetos fronteiriços (STAR; GRIESEMER, 1989), elementos (nesse caso simbólicos) que podem conectar dois ou mais mundos satisfazendo as necessidades interpretativas de todos os lados implicados sem que haja necessariamente imposição de significados de parte a parte.

\section{Espaços, interlocutores e modalidades de $\mathrm{CMC}^{10}$}

Adotei, então, como estratégia de pesquisa, pedir a T. que me ajudasse a construir mais desses objetos, um dos quais foi o mapa que aparece na Figura 2: uma representação mista (topológica-topográfica) do "território social" abrangido pelos seus hábitos de comunicação mediada por computador. Tratase de um objeto fronteiriço justamente porque pude satisfazer, por meio dele, uma necessidade informativa do pesquisador, enquanto T. satisfazia sua necessidade de conhecer, naquele momento, o que seria o seu "território subjetivo".

\footnotetext{
${ }^{10}$ Alguns nomes de lugares foram omitidos para preservar tanto quanto possível o anonimato do colaborador.
} 


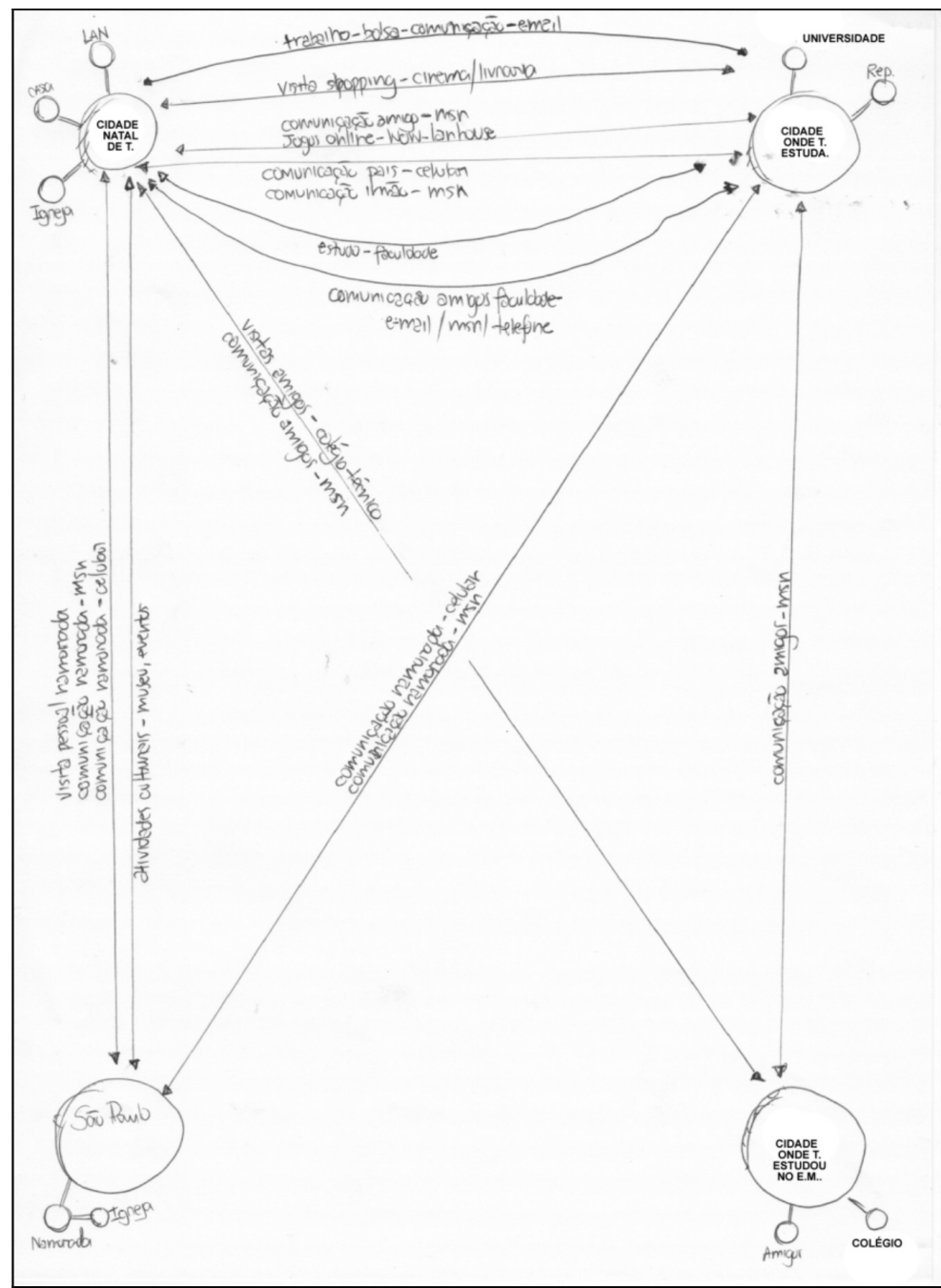

FIGURA 3 - Distribuição espacial das práticas, interlocutores e modalidades de CMC no quotidiano de T.

Havia também, nesses registros de navegação, certos “saltos temáticos" ou mesmo saltos entre línguas e entre linguagens: de "condutas massificadas" para "supernatural: 2 temporada" para "Sending HTML content in an email using PHP”, por exemplo. Esses "saltos", contudo, podiam ser explicados pelo fato de que T. ajudava os colegas que estavam em outros lugares físicos, em especial sua namorada, que ainda cursava o ensino médio, a realizarem trabalhos escolares via MSN, ao mesmo tempo em que desempenhava suas 
próprias atividades de leitura e escrita. $\mathrm{O}$ mesmo, deve-se observar, acontecia quando era T. quem necessitava de ajuda para suas tarefas escolares, profissionais, ou mesmo quando seu personagem do jogo decidia montar uma equipe para fazer uma ride em um calabouço.

Assim como sua presença social se ramificava por muitos lugares, eram muitos os lugares de onde vinham as competências e recursos que T. utilizava, a cada momento, para constituir-se como interlocutor singular, desde os softwares, conexóes e arquiteturas que lhe permitiam dizer-escrever a distância, até vozes que adicionava às suas conversas por meio de hiperlinks, como mostra o excerto 3:

\section{Excerto 3}

T. explica o link da Wikipédia usado durante uma interação via MSN T. - é... começamos a conversar sobre a festa, né? daí eu falei: "ah, aconteceu isso, né?" ela: "é verdade..." daí eu falei: "isso é uma parafilia...”, daí ela "o que é isso?" daí eu fui na wikipédia e mandei o link, né? daí ela: "nossa, mas que tipo aconteceu?" daí eu procurei lá o tipo e mandei e ela achou engraçado, mas não concordou que era aquilo.

Nesse caso, como em outros, ficava cada vez mais claro que $T$. não apenas participava de diferentes grupos: ele era um "coletivo" e, apenas por isso, e pelo modo como concatenava essas entidades, estendendo-se por domínios, espaços, linguagens, tecnologias e letramentos diversos, ele podia ser reconhecido por seus interlocutores, e por mim mesmo, como T., sujeito singular.

Finalizo essa vinheta esclarecendo que T. não era um desajustado que "substituía" os espaços de sociabilidade usuais pelos espaços fantasiosos da Internet. Ao contrário: era um jovem altamente responsável e motivado, com projetos definidos para o futuro e responsabilidades no presente. Como bem ilustra a Figura 2, ele usava a comunicação mediada por computadores justamente para manter esses diferentes espaços à sua disposição e para manter-se à disposição das relações sociais que mantinha neles, continuamente: ele usava os "novos letramentos" para construir "novas espacializaçōes" (geográficas, temáticas, discursivas, etc.), alternativas às que lhe impunham a escola, o trabalho, a família, os pedágios, as tarifas de celular, entre outros "fatores contextuais".

Nesse caso, o desajuste estava, provavelmente, em meu próprio olhar sobre letramentos em contextos, como sugere a perplexidade registrada em minhas notas de campo sobre a vez em que estive com T. e sua namorada na 
lanhouse já mencionada. Todos os presentes ali, embora amigos ou conhecidos entre si, tinham os corpos voltados para cubículos nos quais havia computadores, tal qual executivos de uma corretora de valores ou funcionários de uma empresa de telemarketing. Havia um evento de letramento em curso, mas eu não conseguia definir o seu contexto!

Diante de minha frustração, T. explicou que geralmente era assim: seus amigos iam à lanhouse para jogar e conversar com outros amigos, cujos corpos estavam em outros lugares, ou na própria lanhouse, mas cuja presença real era sentida dentro do jogo. As conversas que eu teria chamado de locais, amparado em uma outra noção de contexto, se davam entre uns poucos rapazes de boné sentados em cadeiras de plástico perfiladas junto à porta da lanhouse, lugar que, segundo T., era reservado aos jogadores de maior reputação na cidade: "Eles não jogam com os newbies, não. Eles ficam olhando pras meninas que passam, e elas olhando pra eles". Meu contexto, portanto, era um também um híbrido. O lugar fora da lanhouse passava por dentro do jogo.

\section{Que entre a Teoria Ator-Rede}

Antes de iniciar esta seção, cabe esclarecer que o objetivo da mesma não será o de estabelecer relações biunívocas entre cada um dos conceitos da TAR aqui apresentados e um respectivo aspecto do caso de T.. Como dito na introdução, o que se busca aqui é simplesmente caracterizar a utilidade e plausibilidade deste tipo de enfoque teórico-metodológico para a pesquisa em (novos) letramento(s). Consciente das lacunas aí deixadas, aposto, em compensação, na possibilidade de mostrar como a TAR poderia, em tese, preencher lacunas outras, nem sempre devidamente reconhecidas.

Se a explicação travestida de narrativa que procurei apresentar por meio da vinheta tiver funcionado, o leitor terá notado que tentei falar de T. tanto como uma rede que conecta textos, máquinas, pessoas, crenças, conceitos, lugares etc., quanto como participante de diversos letramentos, compostos, por sua vez, de elementos heterogêneos atuando uns sobre os outros, entre os quais o próprio T. Falei, enfim, de um sujeito e de seus letramentos como atores-redes.

Junto com a noção de ator-rede, a ser melhor detalhada mais adiante, a TAR oferece uma série de princípios radicais que é preciso destacar. O primeiro desses princípios é o da concepção performativa do social. Trata-se, segundo Latour (2005), de abdicarmos da ideia de que haveria forças sociais ostensivas embutidas em categorizaçōes sociológicas (do tipo classe e gênero), em favor de uma visão segundo a qual a sociedade é construída continuamente por 
disputas em torno de sua organização social realizadas por meio de enunciados que são tornados materialmente estáveis e articulados entre si por meio de atores não humanos (STRUM; LATOUR, 1987). ${ }^{11}$

Nos estudos sobre inovaçôes científicas e tecnológicas onde a TAR nasceu, essa concepção é traduzida nos termos das controvérsias envolvidas na construção de um fato científico ou máquina inovadora, nas quais humanos e não humanos são vistos como portadores do mesmo status sociológicoantropológico (embora, obviamente, tenham atributos e capacidades diferenciadas). ${ }^{12} \mathrm{~A}$ isso a TAR dá o nome de princípio da simetria generalizada, e, por consequência disso, trabalhar com o conceito de actante, emprestado da semiótica francesa, em lugar do conceito de ator social, ${ }^{13}$ usado em outras sociologias..

Chamar tanto humanos como não humanos de actantes implica dotar os não humanos de agentividade, uma noção contraintuitiva, mas fácil de acessar quando consideramos que coisas como bactérias, textos, ideias e teclados de computador podem simplesmente passar adiante uma ação que lhes foi transmitida sem deformação (nesse caso, a TAR os chamará de intermediários), mas também podem resistir a essa ação ou desviá-la (nesse caso, serão mediadores). Transmitir, deformar e resistir são, nesse caso, açōes que

${ }^{11}$ Tal noção guarda, certamente, uma relação com a afirmação de Prior (2009, p. 39, nota de fim n. 9) de que sistemas de gêneros (e/ou de atividade) podem ser vistos como atores-redes, com consequências que merecem ser avaliadas, o que convém apontar aqui, já que se falará em gênero mais adiante (para uma proposta de estudo da relação entre gêneros e atores-redes vinculada a esta pesquisa, ver BUZATO, no prelo). Contudo, quando Strum e Latour (1987) se referem a enunciados tornados estáveis e articulados entre si, não têm em mente, necessariamente, o conceito de gênero ou de sistemas de gêneros/atividade, mas a noção mais genérica de que enunciados podem ser traduzidos/deslocados por outras materialidades que não apenas a da linguagem e por outros atores que não apenas os humanos. Isso está melhor desenvolvido em textos posteriores a Strum e Latour (1987), como em Latour (1992), por meio do conceito de delegação.

${ }^{12}$ Por exemplo, admite-se que tanto humanos como não humanos tenham volição e capacidade de opor resistência, mas considera-se que apenas humanos dispóem da capacidade de raciocinar.

${ }^{13}$ Enquanto a noção de ator social pressupõe um ser humano guiado por forças sociais externas e prévias à sua existência, um actante pode ser qualquer entidade (pessoas, máquinas, ideias, micróbios, textos etc.) participante de uma rede de associaçōes em que a ação é circulada e ordenada de forma mais ou menos estável. 
refletem interesses ${ }^{14}$ desses não humanos. São esses interesses que o cientista e o engenheiro necessitam, de alguma forma, cooptar e traduzir em sua própria linguagem, alistando esses não humanos, assim como muitos humanos, em seu empreendimento "global" que redundará em uma máquina, fato científico ou instituição. Nada impede, porém, que um ator (humano ou não humano) agregado ao empreendimento como intermediário passe a comportar-se como um mediador, pois, sendo todo ator também uma rede, seus interesses podem conectá-lo a outras translações, concorrentes com aquela na qual até então ele se comportava como intermediário.

Se voltarmos por um momento à vinheta, veremos que T. comportavase como intermediário em certos letramentos que circulavam por ele. Isso acontecia, por exemplo, quando ele preenchia um formulário eletrônico qualquer exatamente como o previsto, de modo que o processo burocrático do qual o formulário fazia parte continuasse em funcionamento. Já quando utilizava um tradutor automático para executar tarefas de tradução a ele designadas pelo professor, ou quando fazia "leituras ocultistas" das situações institucionais em que estava envolvido (na família, no trabalho e na escola), T. comportava-se como intermediário, isto é, retraduzia a tarefa escolar ou a situação institucional em sua própria linguagem, enquanto ator alistado por outros letramentos (atores-redes).

Da mesma forma, podemos tomar alguns dos não humanos enredados no ator-rede T. como intermediários (tais como partes de códigos fonte que ele obtinha na Internet ou por amigos da área de computação para estabilizar o comportamento das páginas de web que produzia em sua atividade profissional) e outros como mediadores (um celular cujo plano de tarifação foi alterado de modo a obrigá-lo a falar com a namorada em horários inconvenientes para ambos, por exemplo.)

O processo pelo qual actantes associam-se de modo a constituir um ator-rede é chamado translação. ${ }^{15}$ Translaçōes se dão em uma sequência de

${ }^{14} \mathrm{Os}$ interesses dos não humanos correspondem àquilo para o quê estão de certa forma propensos, ou não, antes de serem agregados a uma translação.

${ }^{15} \mathrm{O}$ termo relativo ao conceito de translação nos estudos de TAR publicados em inglês é "translation", que aceita em português as traduçôes "traduzir" e "transportar", um fato já explorado por outros campos do saber como, por exemplo, nos estudos pós-coloniais, que tratam de traduções culturais como espaços de transporte de significados entre culturas. Isso exprime muito bem o duplo significado dos processos de translação na TAR, vistos como, ao mesmo tempo, 'transladar', no sentido de 
quatro momentos. No primeiro momento, chamado problematização, um ator-focal define um problema e alega ter a solução para ele. Com base nessa problematização, ele define as identidades e os interesses dos demais atores que serão envolvidos, e os persuade a agirem de determinada maneira, tornandose, eventualmente, seu porta-voz.

No caso de T., a problematização estava ligada à sua convicção de que as pessoas, especialmente as mais velhas e as autoritárias, são injustas em seus julgamentos a respeito dos outros e, basicamente, cegas também a respeito do que acontece à sua volta. Tais pessoas, para ele, seriam como personagens de RPG, que agem dentro do enredo do jogo, mas não compreendem a realidade "oculta" por trás do jogo, correspondente ao que fazem e sabem os jogadores.

No segundo momento da translação, chamado de persuadir aliados (Intéressement), os interesses dos atores humanos e não humanos convocados para a translação vão convergir com os do ator-focal à medida que este seja capaz de traduzir em sua linguagem os interesses dos outros actantes. Para convencê-los, o ator-focal terá que de alguma forma excluir da translação todas as vozes dissuasivas vindas de fora, e todas as vozes discordantes vindas de dentro do coletivo. Uma vez interessados, os actantes são fixados em seus lugares e comprometem-se a cumprir o papel para eles estabelecido.

O terceiro momento da translação é o envolvimento (enrollment), no qual os atores aceitam os papéis a eles atribuídos pelo ator-focal, após a realização de atividades interativas/participativas em que vão se conhecendo e compartilhando seus interesses com os demais atores. Esse momento incluirá provas de força, isto é, experimentos ou outros tipos de "julgamentos" em que os atores demonstram serem capazes de exercer a identidade a eles confiada por meio de performances.

No caso de T., os aliados não humanos incluíam canções de black metal, sistemas de RPG, a literatura de Álvares de Azevedo, conhecimentos de ocultismo e mitologia, e, claro, o computador conectado à Internet que lhe permitia reuni-los e mantê-los articulados entre si a longas distâncias espaciais e temporais. As atividades interativas pelas quais esses aliados puderam se conhecer e compartilhar seus interesses incluíram, evidentemente, diversos eventos de letramento, dos quais muitas vezes resultaram textos, como o do

deslocar ou trazer para perto de si um conjunto de entidades que estavam dispersas, e 'traduzir', no sentido de expressar em uma linguagem particular aquilo que outros elementos dizem e querem em suas próprias linguagens. 
Excerto 1, por exemplo. Na quarta etapa, mobilização dos aliados, a rede terá crescido com a adesão dos atores que passaram a atuar como porta-vozes de outros coletivos. Para que os interesses de todos esses coletivos permaneçam alinhados na direção prevista na problematização, o ator-rede central precisará lidar com o problema da ação distribuída e à distância, nos múltiplos sítios que o constituem (LATOUR, 2000). A Figura 3 mostra uma das maneiras pelas quais T. mobilizava a si e a seus aliados por diferentes sítios físicos e virtuais utilizando variados meios de transporte e comunicação. Como atesta o episódio da lan house descrito no final da vinheta, seria um erro isolar o físico do virtual nesse mapeamento, embora T. tenha, ele mesmo, optado por representar lugares físicos como círculos e pelo menos um lugar da Internet o mundo de MMORPG - como uma linha.

Na Figura 4, abaixo, vê-se outra dimensão dessas circulações, isto é, vêse como uma variedade de textos e outros recursos midiáticos funcionavam como objetos fronteiriços, conectando diferentes sítios institucionais, ou, se preferirmos, diferentes domínios da vida social de $\mathbf{T}$., ainda que, em cada um desses sítios, seja usual pensarmos em um T. discreto e isolável dos outros por ocupar uma "posição" diferente.

\section{Domínios da vida de T. e objetos fronteiriços}

Claramente, o que se propóe aqui é aproximar os conceitos de translação e, portanto, de ator-rede, ao de subjetividade, no sentido de que a subjetividade possa ser encarada como um efeito das múltiplas conexôes que habilitam um sujeito a circular como "alguém" em algum contexto. Tal capacidade, fique claro mais uma vez, não reside nem no sujeito visto como entidade discreta, nem na "estrutura social" supostamente emanante de outro plano, mas estaria vinculada à circulação contínua de recursos específicos que lhe servem de subjetificadores, circulaçôes sem as quais esse "alguém" não poderia ser "individualizado, espiritualizado, interiorizado" (LATOUR, 2005, p. 212).

Nada na TAR impede que categorias sociológicas tais como gênero, classe, etnicidade etc. sejam tomadas como subjetificadores; o que a teoria não permite é tomá-las como determinantes da ação dos atores. Isso é o mesmo que afirmar que, na TAR, categorias sociológicas não são ignoradas, mas apenas tomadas como "efeitos da circulação" de dados e métricas sociológicos 
(LATOUR, 2005), ${ }^{16}$ que convivem com muitos outros efeitos de muitas outras circulações.

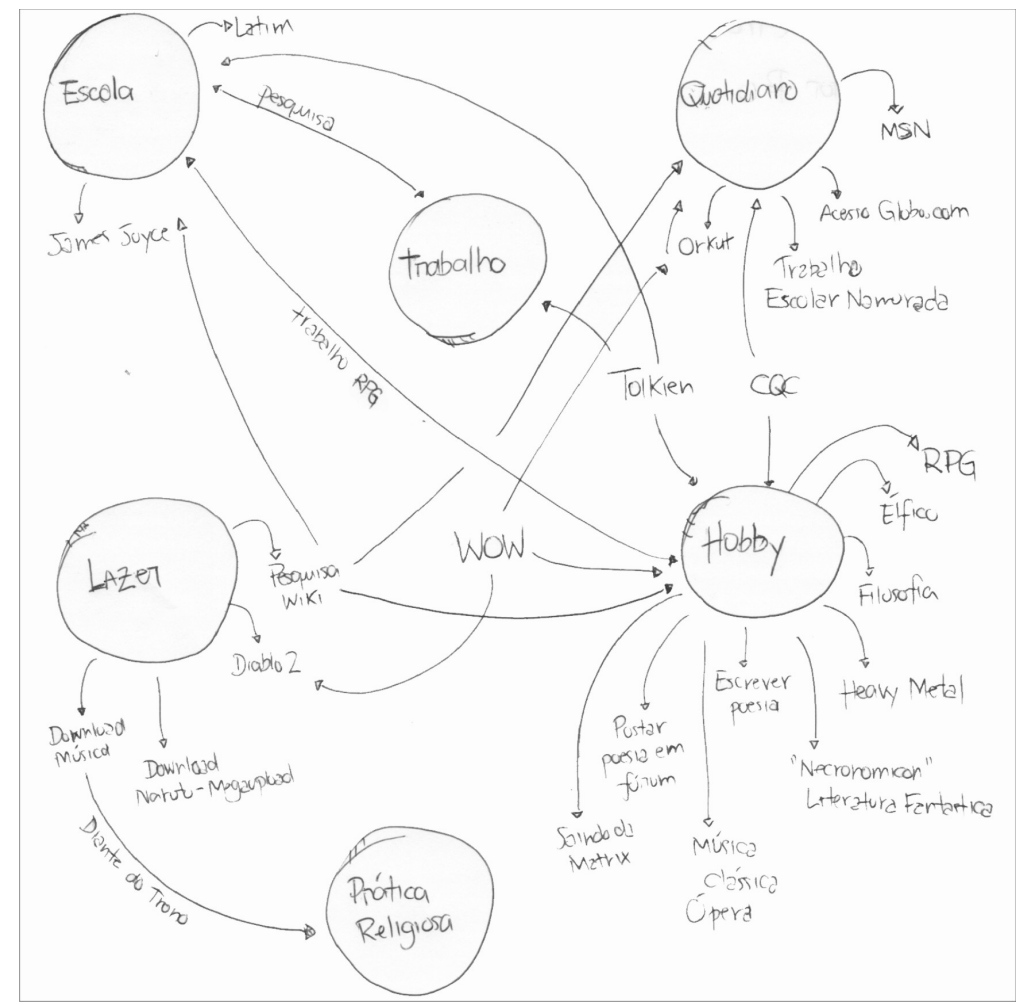

FIGURA 4 - Textos e atividades que conectam domínios da vida social de T.

No caso de T., como visto na vinheta, procurei destacar subjetificadores oriundos de outras práticas que não as dos sociólogos, e que aparentavam, inicialmente, ser incompatíveis entre si do ponto de vista do pesquisador,

${ }^{16}$ Particularmente porque nossas noções de aprendizagem, desenvolvimento e educação são, no mais das vezes, vinculadas a narrativas sobre classe, gênero, grau de instrução e assim por diante, é que autores como Nespor (1994) afirmam que teorias como a TAR são úteis aos que pensam em letramento e educação. Mais concretamente, para o autor, tais teorias nos permitiriam ir além da noção, já fundamentada por estudos de antropologia cognitiva, de que a aprendizagem e o conhecimento são produtos da prática social situada, no sentido de compreender como tais aprendizagens e conhecimentos são organizados em redes que atravessam práticas e espaciotemporalidades. 
apoiado em sua problematização inicial sobre o que estava havendo. Foi apenas quando T. passou de sujeito de pesquisa (discreto e finito) a ator-focal de uma translaçâa, por meio da manobra metodológica já aludida, que o pesquisador conseguiu perceber a consistência dessas circulaçōes.

Finalmente, assim como os sujeitos, também os letramentos podem ser vistos, a partir da TAR, como translaçôes, algumas já estabilizadas e tornadas "caixas pretas", como boa parte dos letramentos escolares, e outras em franco processo desestabilização e reestabilização, como já mostraram autores como Chartier (1998) e Bolter (2002), a partir de outros aportes teóricos. Quando Coiro et al. (2008) dizem que letramento tornou-se um dêitico, talvez estejam apenas repetindo o que já sabemos desde que começamos a compreender letramentos como práticas múltiplas e "situadas": letramentos dependem de contextos ao mesmo tempo em que os produzem. O ponto é, como espero ter demonstrado, que talvez possamos avançar nesse raciocínio ao priorizar não os contextos como contêineres (LEANDER; LOVVORN, 2006), mas as circulaçôes e des-re-contextualizaçôes que produzem e são produzidas por sujeitos e letramentos enquanto redes heterogêneas.

Essa ênfase na tradução e deslocamento da ação e dos significados com base na TAR já se reflete em um corpo limitado, porém interessante, de estudos sobre letramento, sendo, provavelmente, os trabalhos de Brandt e Clinton (2002), Hamilton (2001), Clarke (2001 e 2002), Barton e Hamilton (2005), Leander e Lovvorn (2006) e Prior (2009) os mais conhecidos. Ainda assim, podemos dizer que são poucos os estudos sobre (novos) letramento(s) que levam a teoria efetivamente às suas últimas consequências.

Brandt e Clinton (2002), por exemplo, usam a TAR para argumentar que os Novos Estudos sobre o Letramento, em seu impulso inicial de combater o determinismo do modelo autônomo, ao qual se contrapuseram, talvez tenham desprezado a importância da dimensão tecnológica do letramento, isto é, de como as circulaçôes de textos e tecnologias em contextos situados criam, inevitavelmente, uma dimensão global para o letramento cujos efeitos necessitam ser explorados.

Hamilton (2001) usa o conceito da translação para demonstrar como ideologias oficiais sobre o letramento foram materializadas por um exame nacional de proficiência em leitura e escrita. Basicamente, a autora demonstra que vozes dissuasivas e controversas, assim como saberes locais e vernaculares, foram sendo excluídos da translação para que um significado particular de letramento pudesse ser estabilizado e perenizado pelo exame em questão. A 
autora, contudo, não parece confiante no que tange aos princípios mais radicais da teoria, como o da simetria generalizada.

Clarke (2001) mostra que a TAR, ou, mais especificamente, a noção de que o poder circula na forma de translaçôes, permite combater modelos de letramentos no plural (e/ou multiletramentos) que pressupõem a ostensividade das forças sociais ou relações de poder que querem explicar. Seu argumento é no sentido de propor que a TAR ofereceria um caminho para a descrição de como, concretamente, certos letramentos (e tecnologias do letramento) se tornam dominantes e influentes enquanto outras são suprimidas ou ignoradas. ${ }^{17} \mathrm{Em}$ texto posterior, contudo, a autora (2002) parece recuar em seu entusiasmo pela TAR, passando a destacar críticas feitas à teoria. ${ }^{18}$

Barton e Hamilton (2005), assim como Prior (2009), reconhecem que a TAR tem um potencial explicativo para o fenômeno da circulação espacial dos enunciados que constitui a produção de um texto e/ou de um letramento, mas não exploram os pontos mais polêmicos da teoria, tais como a concepção performativa do social. Leander e Lovvorn (2006) vão um pouco além, no sentido de mostrarem como textos e letramentos digitais são articulados por cadeias de elementos humanos e não humanos, e como a TAR mina a concepção de contexto como contêiner para as práticas sociais. Porém, não tiram tanto proveito quanto poderiam ter tirado da capacidade da TAR para explicar os processos de ressemiotização e transmidiação que constituem fundamentalmente as práticas de letramento enfocadas em seu estudo.

Assim como os trabalhos que acabo de citar, este não pretende dar um salto qualitativo nas explicações sobre o(s) (novos) letramento(s) com base em apenas um caso e em uma compreensão ainda inicial da teoria. Espera-se,

${ }^{17} \mathrm{O}$ presente trabalho não tinha como objetivo fazer tal descrição, de certa forma já tentada por Hamilton (2001), mas quer-se crer que atende a um objetivo auxiliar àquele: encontrar maneiras de mostrar como sujeitos letrados e letramentos constituem-se mutuamente ao longo de diferentes trajetórias, que podem ou não ser capturadas por translações maiores e mais poderosas, estabilizando-se (ou legitimando-se) dessa maneira.

${ }^{18}$ Tais críticas são, em geral, (i) contra a noção de simetria generalizada, entendida, erroneamente, na maioria dos casos, como não diferenciação entre humanos e não humanos em suas naturezas e possibilidades de ação, coisa que a TAR efetivamente nunca defendeu; ou (ii) relativas a uma suposta "negligência à historicidade" por parte da TAR (MIETTINEN, 1999), quando, em verdade, o que a TAR rejeita é qualquer forma de "determinismo histórico" (LATOUR, 1996; 2005). 
porém, que, como os demais, este trabalho tenha contribuído para a construção de condições necessárias para que se avance mais nesse sentido, mostrando como alguns aportes da teoria viriam a calhar.

\section{Considerações finais}

Conectar sujeitos e letramentos entre si tomando-os como atores-redes é uma maneira sofisticada de afirmar que, ao servir-se de um letramento, um sujeito letrado também serve a este letramento. Trata-se de uma forma relativamente pouco usual de, como preconiza a TAR, negar uma suposta dicotomia entre sujeito e estrutura, sem com isso querer negar a existência de desigualdades de poder entre os atores envolvidos. Basta citar aqui, como exemplo, o fato de que todas as vezes que utilizamos um motor de buscas na web e clicamos em um resultado fornecido por ele, estamos não apenas "baixando" subjetificadores para uso local como também estamos sendo mobilizados, via AdSense, ${ }^{19}$ enquanto aliados da empresa dona do serviço de buscas em questão. Aliados porque enviamos de volta à empresa, a cada busca que fazemos, e a cada link que seguimos, uma informação valiosa que, acumulada, embaralhada, e reprocessada continuamente, será utilizada na construção de um saber sobre nós mesmos que atende a uma problematização equivalente ao business plan da companhia (BUZATO;SEVERO, 2010).

Podemos nos perguntar continuamente quanto vale o Google em nossas vidas sem nunca nos ocorrer que é possível perguntar também quanto valemos, enquanto aliados, para atores-redes como a Google, seus engenheiros e seus anunciantes. Tal como os sociólogos que nos dizem a que classe e gênero pertencemos, os cientistas, economistas, contadores e investidores vinculados à Google nos permitem saber que somos "usuários", "clientes" e assets, e nos informam, até mesmo, que interesses (por amigos, produtos ou informaçôes) deveríamos ter. Basta, contudo, que desabilitemos os cookies em nossos browsers para, imediatamente, sermos desconectados da translação, a qual, contudo, continuará tranquilamente, porque não somos capazes de, todos juntos, transformarmo-nos em intermediários, forçando uma reproblematização.

${ }^{19}$ Trata-se de um mecanismo pelo qual o motor de buscas detecta a relevância de uma busca feita pelo usuário para um anunciante que assina o serviço e busca unir os dois por meio de um link patrocinado. Ver mais em <https://www.google.com/ adsense/support/bin/topic.py?hl=pt-BR\&topic=13488>. 
Convém, portanto, citar, ainda que brevemente, este importante ponto da teoria: para a TAR, o que poderíamos chamar de emancipação não se confunde com uma ruptura de vínculos entre os sujeitos e as estruturas que constrangem sua ação já que, como dito anteriormente, sem vínculos não há ação, nem há sujeito. Emancipar-se seria, isto sim, uma questão de trocar vínculos piores por vínculos melhores segundo problematizaçôes locais (LATOUR, 2005, p. 207). Pode-se olhar por esse prisma o caso de T., visto, então, não como um "alienado", "romântico" ou "sonhador" que preenche o tempo com poemas, jogos e bate-papo, mas como um letrado que aprendeu a manejar uma variedade de aliados e objetos fronteiriços para renegociar sua identidade e seu papel em translações (letramentos) mais poderosas e extensas do que ele, tornando-as mais convergentes com sua forma de problematizar o mundo.

Vale ainda, nestas consideraçôes finais, sintetizar alguns pontos que poderiam interessar a futuros estudos realizados dentro da mesma perspectiva teórico-metodológica:

(i) sujeitos letrados (nas salas de aula, ou em qualquer outro lugar) se constituem localmente por meio de vínculos que se espalham em muitas direçôes; logo, se queremos compreender como esses letramentos servem a esses sujeitos, e propor reproblematizações que julgamos úteis e educativas, não convém simplesmente romper ("desliguem os celulares!") ou desconsiderar ("Só me interessam suas próprias palavras!") os vínculos já existentes: convém, isto sim, procurar formas de lidar com a complexidade gerada no exato momento em que decidimos assumir tais vínculos para deles nos servirmos localmente, sem, contudo, cair na ilusão de que a totalidade do que está acontecendo em um determinado "contexto situado" possa ser controlada, ou mesmo descrita;

(ii) os contextos que produzem e são produzidos por práticas de letramento não determinam a aprendizagem ou as interpretações dos sujeitos em qualquer sentido simplista, mas, para dizer o mínimo, os letramentos - desde sempre, mas mais tangivelmente hoje - constituem processos de contextualização-descontextualização-recontextualização que engendram aprendizagens e subjetividades precariamente estabilizadas;

(iii) qualquer empreendimento local, inclusive os educacionais e profissionais, é sempre produzido a distância, sempre estabelecido em relação a um global que não está em um "plano superior", mas constitui uma outra escala da mesma rede (LATOUR, 2005). Assim, o que o global e a Internet fazem conosco é exatamente o que fazemos com e por eles, para o bem e para o mal. 
Não poderia finalizar este trabalho sem mencionar algo que o leitor, certamente, já terá notado: como pesquisador, sou, eu também, um ator-rede, e minha pesquisa, como qualquer outra, é também uma translação sujeita a desintegrar-se prematuramente, a menos que consiga, porventura, interessar a alguns daqueles que agora a leem, traduzindo parte de seus interesses. Junto com o receio de ver o que pretendi empreender tornar-se um punhado de entidades dispersas, essa constatação ao menos me traz a boa sensação de que ganhamos todos, eu e os leitores, um reforço adicional para nossa reflexividade.

\section{Referências}

BARTON, David; HAMILTON, Mary. Literacy, Reification and the Dynamics of Social Interaction. In: BARTON, David; TUSTING, Karin (Org.). Beyond Communities of Practice: language, power, and social Context. New York: Cambridge University Press, 2005. p. 14-35.

BOLTER, Jay David. Writing space: Computers, Hypertext and the Remediation of Print. Mahwah: Lawrence Erlbaum, 2002.

BRANDT, D.; CLINTON, Katie. Limits of the Local: Expanding perspectives on literacy as a social practice. Journal of Literacy Research, n. 34, v. 3, p. 337356, 2002.

BUZATO, Marcelo E. K. Multimodalidade e Práticas digitais: O papel dos objetos fronteiriços. In: Anais do II Simpósio Hipertexto e Tecnologias na Educação. Recife: Universidade Federal de Pernambuco, 2008. v. 1, p. 1-18. Disponível em: <http://www.ufpe.br/nehte/simposio2008/anais/Marcelo-Buzato.pdf>. Acesso em: 19 set. 2011.

BUZATO, Marcelo E. K. Dinâmicas de apropriação e a constituição de transletramentos no contexto de um telecentro comunitário. In: Anais do VI Congresso Internacional da Abralin. João Pessoa - PB, 2009(a). p. 2749-2758.

BUZATO, Marcelo E. K. Letramento e inclusão: do estado-nação à era das TIC. DELTA - Documentação de Estudos em Lingüistica Teórica e Aplicada, v. 25, n. 1, p. 1-38, 2009 (b).

BUZATO, Marcelo E. K. Práticas de letramento na ótica da Teoria Ator-Rede: casos comparados. Calidoscopio, São Leopoldo (RS), 2012. No prelo.

BUZATO, Marcelo E. K.; SEVERO Cristine G. Apontamentos para uma análise do poder em práticas discursivas e não-discursivas na Web $2.0 \mathrm{In}$ : Anais online do IX Encontro do CELSUL (Círculo de Estudos Linguísticos do Sul), Palhoça - SC, 2010. Disponível em: <http://www.celsul.org.br/Encontros/09/artigos/ Marcelo\%20Buzato. pdf>. Acesso em: 20 fev. 2011. 
CHARTIER, Roger. A aventura do livro: do leitor ao navegador. Tradução de Reginaldo de Moraes. São Paulo: Fundação Editora da UNESP, 1998.

CLARKE, Julia. Using Actor-Network Theories for the Study of Literacy Events and Practices in Global and Local Settings. International Literacy Conference. Cape Town, 2001. Disponível em: <http://www.ched.uct.ac.za/literacy/Papers/ ClarkePaper1.html>. Acesso em: 10 maio 2007.

CLARKE, Julia. A new kind of Symmetry: Actor-Network Theories and the new Literacy Studies. Studies in the Education of Adults. v. 34, n. 2, p. 107-122, 2002. COIRO, Julie. et al. Central Issues in new Literacies and new Literacies Research. In . (Ed.). The Handbook of Research in new Literacies. Mahwah - NJ: Erlbaum, 2008. p. 1-21.

HAMILTON, Mary. Priviledged Literacies: Policy, Institutional Process and the Life of IALS. Language and Education, v. 15, p. 178-196, 2001.

IEDEMA, Rick A. M. Multimodality, Resemiotization: Extending the Analysis of Discourse as Multi-Semiotic Practice. Visual Communication, v. 2, n. 1, 2003. p. 29-57.

LATOUR, Bruno. Where are the Missing Masses? The Sociology of a Few Mundane Artifacts In: BIJKER, Wiebe; LAW, John (Ed.). Shaping Technology/ Building Society: Studies in Sociotechnical Change. Cambridge: MIT Press, 1992. p. 225-258.

LATOUR, Bruno. On Actor-Network Theory: A Few Clarifications. Bonn, Soziale Weltz-Zeitschrift fur Sozialwissenschaftliche forschung und praxis, v. 47, n. 4, p. 369-81, 1996, Disponível em: <http://www.nettime.org/Lists-Archives/ nettime-l-9801/msg00019.html>. Acesso em: 15 mar. 2006.

LATOUR, Bruno. Ciência em ação: como seguir cientistas e engenheiros sociedade afora. São Paulo: Editora Unesp, 2000.

LATOUR, Bruno. Reassembling the Social: an Introduction to Actor-NetworkTheory. New York: Oxford University Press, 2005.

LEANDER, Kevin; LOVVORN, Jason. Literacy Networks: Following the Circulation of Texts, Bodies, and Objects in the Schooling and online Gaming of One Youth. Cognition and Instruction, n. 24, v. 3, 2006. p. 291-340.

LEMKE, Jay. Multimodal Genres and Transmedia Traversals: Social Semiotics and the Political Economy of the Sign. Semiotica. n. 173-1, v. 4, 2009. p. 283-297.

MIETTINEN, Reijo. The Riddle of Things: Activity Theory and ActorNetwork Theory as Approaches to studying Innovations. Mind, Culture and Activity, n. 3, v. 6, 1999. p. 170-195. 
NESPOR, Jan. Knowledge in Motion: Space, Time and Curriculum in Undergraduate Physics and Management. London: Falmer Press, 1994.

PRIOR, Paul. From Speech Genres to Mediated Multimodal Genre Systems: Bakhtin, Voloshinov, and the Question of Writing. In: BAZERMAN et al. (Ed.). Genre in a Changing World. Fort Collins: WAC Clearinghouse and Parlour Press, 2009. p. 17-34.

STAR, Suzan. L.; GRIESEMER, James. R. Institutional Ecology, 'Translations' and Boundary Objects: Amateurs and Professionals in Berkeley's Museum of Vertebrate Zoology, 1907-39. Social Studies of Science, v. 19, n. 3, 1989. p. 387-420.

STRUM, Shirkey; LATOUR, Bruno. The Meanings of Social: from Baboons to Humans. Social Science Information, v. 26, 1987. p. 783-802.

Recebido em 24/04/2011. Aprovado em 20/01/2012. 